\title{
The Importance of Anatomical Terminology Employment in Health Sciences
}

\section{A Importância do Emprego da Terminologia Anatômica nas Ciências da Saúde}

\author{
Giuliano Roberto Gonçalves ${ }^{\text {III }}$ (ID \\ Richard Halti Cabral ${ }^{I I I}$ iD \\ Leandro Henrique Grecco ${ }^{I V}$ (iD
}

Dear Editor,

Anatomical Terminology (TA) is a unique collection of technical terms that allow communication in anatomy and medicine worldwide ${ }^{1,2}$. However, the current Anatomical Terminology also contains some internal inconsistencies and discrepancies in relation to clinical terminology. Thus, several terms are not directly related to the names of anatomical structures and / or the names of corresponding physiological and pathological conditions. In addition, during clinical practice, many anatomical terms have been replaced by new clinical expressions. These terminological discrepancies may hinder learning and teaching anatomy in medicine and other courses in the health field. These "mismatches" of terms generate a lot of confusion due to different origins and languages ${ }^{1}$.

International Anatomical Terminology (IAT) is a fundamental process for medicine and other health professions, where "the act of standardizing a term is more related to standardizing and making it uniform and even harmonizing it than the act of imposing a form through normative procedures ${ }^{33,4}$. It is important that students in the health area have a good knowledge and understanding of basic anatomical terms, taking into account that anatomy constitutes the basis for the practice of medicine and other health courses. Anatomical understanding makes the professional understand a patient's illness, either by clinical examination or by using the most advanced imaging techniques ${ }^{2,5}$. It is important not only to understand anatomical terms, but to place these terms within their own context, that is, to give an appreciation of how the human body functions both in health and in disease ${ }^{1}$. The precise use of anatomical terms by health professionals allows accurate communication between colleagues, both nationally and internationally. Thus, a good knowledge of Anatomical Terminology requires an understanding of the context in which terms can be remembered ${ }^{2,3}$.

Without Anatomical Terminology, it is not possible to discuss or accurately record the abnormal functions of the joints, the actions of the muscles, the change in the position of the organs or the exact location of edema or tumors ${ }^{4}$. The ability to correctly interpret a clinical observation is, therefore, the goal of the understanding of anatomical terminology and solid concepts.

The current inconsistency between anatomical terminology and clinical nomenclature is seen as one of the biggest problems that hinder medical education ${ }^{5}$. Medical students, when starting clinical internships, encounter difficulties, as the terms used by their clinical instructors often do not follow Anatomical Terminology, and this spreads, becoming their permanent language ${ }^{3,4,5}$. Sometimes, it seems that each clinician has their preference, but it is worth mentioning that Anatomical Terminology is an official document that must be obeyed by the authors of books, professors and students in the health field, using the uniform term for each structure ${ }^{2,5}$. Another important issue reported in the work of Novak and collaborators is that:

[...] the terms used in medical publications suffer variations when comparing different authors and different journals. The lack of uniformity compromises how words are reproduced, as several currents are created, each following the ideology that it chooses appropriate. In addition, it is more difficult when searching by keyword, considering that the same structure displays several spellings. ${ }^{5}$.

Editors and reviewers of specialized journals call attention to the anatomical terminological indiscipline of most authors and translators, being a constant in works sent to publications. In linguistics, it is not convenient to say that a certain word is right or wrong, but if it is appropriate or inappropriate to the standards ${ }^{2,3,5}$. The

Received on $5 / 31 / 20$

Accepted on 7/13/20

REVISTA BRASILEIRA DE EDUCAÇC̄O MÉDICA

44 (4) : e112; 2020
${ }^{1}$ Faculdade São Leopoldo Mandic, Araras, São Paulo, Brazil

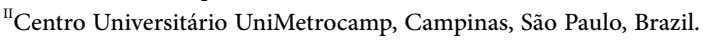

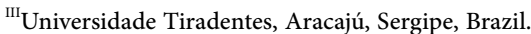

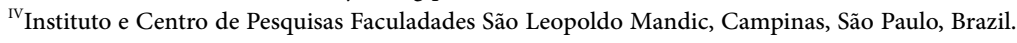


scientific language must be accurate, in order to avoid mistakes; simple, to facilitate understanding; and concise, in order to save searching and reading time, as well as space in publishing. In addition, the words must be carefully observed, "with the same accuracy with which the symbols in mathematics are used"

This text is not intended to exhaust the subject nor to recommend an immediate change of the current clinical nomenclature, but only to alert and make the reader and students aware of the frequent use of inappropriate or outdated terms in the description of the morphology, location and function of anatomical structures, as well as of the exaggerated use of non-informative eponyms. The nomenclature based on the correct anatomical orientation and based on the official and current Anatomical Terminology facilitates not only the spatial location of the structures, but also the relationships with the other structures and organs $s^{2,3,4}$.

\section{REFERENCES}

1. Terçariol SG. Anatomia Humana: História e Etimologia. $1^{\text {a }}$ ed. Araçatuba: Gráfica Moço, 2018.

2. Sociedade Brasileira de Anatomia. International Anatomical Terminology. Anatomical CdT. São Paulo: Editora Manole; 2001.

3. Mylos R. Mylos Root in Terminology Anatomica. J Int J Morphol. 2020;38(1):126-8.
4. Galic BS, Babovic SS, Vukadinovic S, Strkalj G. Clinical Relevance of Official Anatomical Terminology: The Significance of Using Synonyms. J International Journal of Morphology. 2018;36(4).

5. Novak EM, Giostri GS, Nagai A. Terminologia anatômica em ortopedia. J Revista Brasileira de Ortopedia. 2008;43(4):103-7.

\section{CONTRIBUTION OF THE AUTHORS}

The three authors participated in the conceptualization, planning, methodology and writing of this work.

\section{CONFLICT OF INTEREST}

We declare that there is no conflict of interest in the topics covered in this work.

\section{MAILING ADDRESS}

Giuliano Roberto Gonçalves. Medicine School São Leopoldo Mandic, Av. Dona Renata, 71, Centro, Araras, SP, Brazil. ZipCode: 13600-001. Email: giulianoanatomia@gmail.com 